\title{
Metabolism of Endogenous Surfactant in Premature Baboons and Effect of Prenatal Corticosteroids
}

\author{
JAN ERIK H. BUNT, VIRGILIO P. CARNIELLI, STEVEN R. SEIDNER, MACHIKO IKEGAMI, \\ J. L. DARCOS WATTIMENA, PIETER J. J. SAUER, ALAN H. JOBE, and LUC J. I. ZIMMERMANN
}

Division of Neonatology, Department of Pediatrics, Sophia Children's Hospital/University Hospital Rotterdam/Erasmus University Rotterdam, Rotterdam, The Netherlands; Division of Neonatology, Department of Pediatrics, University Hospital Padova, Padua, Italy; University of Texas Health Science Center, San Antonio, Texas; Pulmonary Biology, Children's Hospital Medical Center, Cincinnati, Ohio; Department of Internal Medicine II, Erasmus University Rotterdam, Rotterdam, The Netherlands; and Department of Pediatrics, University Hospital Groningen, Groningen, The Netherlands

\begin{abstract}
We studied the synthesis of surfactant and the effect of prenatal betamethasone treatment in vivo in very preterm baboons. Ten pregnant baboons were randomized to receive either betamethasone (beta) or saline (control) 48 and $24 \mathrm{~h}$ before preterm delivery. The newborn baboons were intubated, treated with surfactant, and ventilated for $6 \mathrm{~d}$. They received a 24-h infusion with the stable isotope $\left[\mathrm{U}-{ }^{13} \mathrm{C}\right] \mathrm{glucose}$ as precursor for the synthesis of palmitic acid in surfactant phosphatidylcholine (PC). Palmitic acid in surfactant PC became enriched $27 \pm \mathbf{2} \mathbf{~}$ after the start of the isotope infusion and was maximally enriched at $100 \pm 4 \mathrm{~h}$. The fractional synthesis rate of PC palmitate in the beta group (1.5 $\pm 0.2 \% / d)$ was increased by $129 \%$ above control $(0.7 \pm 0.1 \% / d)(p<0.02$, MannWhitney $U$ test). The absolute synthesis rate of PC in the beta group $[1.6 \pm 0.3 \mu \mathrm{mol} / \mathrm{kg} / \mathrm{d}] \mathrm{was}$ increased by $128 \%$ above controls $[0.7 \pm 0.2 \mu \mathrm{mol} / \mathrm{kg} / \mathrm{d}](\mathrm{p}<0.02)$. These data show that the synthesis of endogenous surfactant from plasma glucose as precursor is a slow process. It is shown, for the first time in vivo, that prenatal glucocorticosteroids stimulate the synthesis of surfactant PC in the very premature baboon. Bunt JEH, Carnielli VP, Seidner SR, Ikegami M, Wattimena JLD, Sauer PJJ, Jobe AH, Zimmermann LJ. Metabolism of endogenous surfactant in premature baboons and effect of prenatal corticosteroids. AM J RESPIR CRIT CARE MED 1999;160:1481-1485.
\end{abstract}

Little is known about surfactant metabolism after preterm delivery of humans or animals. In term and preterm monkeys and lambs with surfactant deficiency, the pool sizes of surfactant in the alveolus increase slowly postnatally $(1,2)$. R ecovery from respiratory distress syndrome (RDS) in monkeys is associated with larger increases in lung pool sizes of disaturated phosphatidylcholine (DSPC) than is nonrecovery from RDS (3). In the preterm human, the accumulation of alveolar surfactant is slow, as shown by a slow postnatal increase in surfactant phosphatidylcholine (PC) concentration in tracheal aspirates (4), and low synthesis rates of surfactant PC (5).

The improved pulmonary function of previously unstressed preterm animals after treatment with prenatal glucocorticoids results primarily from structural changes of the lungs that include increased lung gas volume, decreased perilobular connective tissue, decreased alveolar wall thickness (6), and induc-

(Received in original form August 19, 1998 and in revised form March 30, 1999) Supported by the Sophia Foundation for Medical Research (SSWO 184) and by the National Institute of Child Health (HL 52635) (The Southwest Foundation for Biomedical Research BPD Resource Center).

Correspondence and requests for reprints should be addressed to LuC J. I. Zimmermann, M.D., Ph.D., Neonatology, Sophia Children's Hospital, Dr. Molewaterplein 60, 3015 GJ Rotterdam, The Netherlands. E-mail: Zimmermann@alkg.azr.nl Am J Respir Crit Care Med Vol 160. pp 1481-1485, 1999

Internet address: www.atsjournals.org tion of antioxidant enzyme activities (7). I mproved pulmonary function also can result from increased amounts of surfactant. In vitro, glucocorticoids increase the activity of a number of enzymes of the surfactant synthetic pathway and increase surfactant phospholipid and protein synthesis, and lamellar body appearance in human fetal lung explants (8-10). However, in most in vivo studies with preterm rabbits, preterm lambs, and very preterm baboons, treatment with betamethasone $48 \mathrm{~h}$ before delivery does not increase surfactant pool sizes of the alveolar lavage and total lung $(2,11,12)$. We reported large increases in surfactant PC pools after birth in both the lung tissue and alveolar pools of preterm ventilated baboons during the first days of life, and pool sizes were not significantly increased by prenatal glucocorticoids (2). A s pool size depends on both synthesis and clearance of surfactant, the measurement of the pool size is not equivalent to the measurement of the production rate. Therefore, it is currently unclear whether prenatal glucocorticoids increase surfactant production after preterm delivery.

We studied postnatal endogenous surfactant metabolism in the very premature baboon and tested the hypothesis that prenatal corticosteroids influence the synthesis of endogenous surfactant in vivo. These studies are comparable to our report of endogenous surfactant metabolism in preterm human infants (5) because we used the same stable nonradioactive isotope, [U $-{ }^{13} \mathrm{C}$ ]glucose, as a precursor for the synthesis of palmitic acid in surfactant $P C$. 


\section{METHODS}

\section{Animal Treatment and Postnatal Care}

A nimal care, fetal treatments, deliveries, and the postnatal studies were performed at the Southwest Foundation for Biomedical Research (San A ntonio, TX) as reported previously (2). A II procedures were reviewed and conformed with A A A LA C guidelines. Pregnancies were dated on the basis of cycle dates and growth parameters determined by prenatal ultrasounds performed at estimated fetal gestational ages of 70 and $100 \mathrm{~d}$. A t $123 \pm 2 \mathrm{~d}$ of gestation (term is $185 \mathrm{~d}$ ) the pregnant baboons were randomly assigned to receive $6 \mathrm{mg}$ of betamethasone (Celestone Soluspan; Schering Pharmaceuticals, K enilworth, $\mathrm{NJ}$ ) or saline by intramuscular injection 48 and $24 \mathrm{~h}$ before delivery. A t delivery, the pregnant baboons were sedated with ketamine (10 mg/kg, intramuscular), intubated, and anesthetized with $1.5 \%$ halothane. The preterm fetuses were delivered by cesarean section at $125 \pm 2 \mathrm{~d}$ gestation and intubated. The newborns received sufactant (100 $\mathrm{mg} / \mathrm{kg}$ ) by tracheal instillation (Survanta; donated by R oss Products, Columbus, $\mathrm{OH}$ ). A t birth, animals received parenteral fluids containing glucose, amino acids, multivitamins, and appropriate electrolytes intravenously; they were not fed, and did not receive lipids.

To study the endogenous surfactant PC palmitate production, all newborn baboons received a constant intravenous infusion of the stable isotope $\left[\mathrm{U}-{ }^{13} \mathrm{C}\right.$ ] glucose for $24 \mathrm{~h}$, starting immediately after birth $(\mathrm{t}=0)$, at a rate of $0.17 \mathrm{mg} / \mathrm{kg} / \mathrm{min}$. A rterial blood $(0.5 \mathrm{ml})$ was drawn at $0,12,18$, and $24 \mathrm{~h}$, for determination of plasma glucose enrichment. Tracheal aspirates were obtained every $12 \mathrm{~h}$ during the study period of $6 \mathrm{~d}$. A fter instillation of $0.5 \mathrm{ml}$ of saline into the endotracheal tube, aspiration was performed with a $5 \mathrm{~F}$ catheter, and the aspirate was frozen.

A t $144 \mathrm{~h}(6 \mathrm{~d})$, the animals were killed with pentobarbital. A Iveolar wash was performed in situ by filling the lungs with $0.9 \% \mathrm{NaCl}$ at $4^{\circ} \mathrm{C}$ and recovering the fluid by syringe (2). The lavage procedure was repeated five times. The lungs were removed, weighed, and homogenized and aliquots were frozen.

\section{Analytical Procedures}

The tracheal aspirates, alveolar washes, lung homogenates, and plasma glucose samples were processed as described previously (5). In brief, blood was collected and directly centrifuged to separate plasma and cells. Plasma was delipidated with chloroform and methanol (13). The water fraction was passed over anion- and cation-exchange resin. The eluate containing the glucose was derivatized to an aldonitril pentacetate derivative (14). A fter thawing, the tracheal aspirate and alveolar wash were vortexed and centrifuged at $450 \times \mathrm{g}$ for $10 \mathrm{~min}$ at $4^{\circ} \mathrm{C}$, and the pellet was discarded. From the tracheal aspirate, alveolar wash, and lung homogenate, lipids were extracted (15). PC was isolated from the lipid extract by thin-layer chromatography (16). The PC was transmethylated to form fatty acid methyl esters (17). The saturated (Sat) PC pool size was measured in the alveolar wash and lung homogenate by treatment of the lipid fractions with osmium tetroxide (18). Saturated PC was isolated by column chromatography using alumina, and quantified by phosphorus assay (19).

\section{Determination of ${ }^{13} \mathrm{C}$ Enrichment}

The ${ }^{13} \mathrm{C}$ enrichment of plasma glucose and of palmitate in surfactant PC was measured by gas chromatography-combustion interface-isotope ratio mass spectrometry (GC-CI-IRMS) (VG Isotech, Middlewich, Cheshire, UK ) as previously described (5). For glucose, $1 \mu \mathrm{l}$ was injected onto a $25 \mathrm{~m} \times 0.25 \mathrm{~mm}, 0.11 \mu \mathrm{m} \mathrm{HT}-5$ capillary column (Scientific G lass E ngineering, V ictoria, A ustralia), with a split ratio of $30: 1$. The oven temperature was isothermal at $220^{\circ} \mathrm{C}$. For PC palmitate analysis, $1 \mu \mathrm{l}$ was injected on a 30-m O mega wax column (Supelco, Z wijndrecht, The $N$ etherlands). The injection and oven temperature were $45^{\circ} \mathrm{C}$ for $2 \mathrm{~min}$ and raised at $15^{\circ} \mathrm{C} / \mathrm{min}$ to $175^{\circ} \mathrm{C}$, held for $15 \mathrm{~min}$ at $175^{\circ} \mathrm{C}$, and subsequently increased by $2^{\circ} \mathrm{C} / \mathrm{min}$ to $240^{\circ} \mathrm{C}$. The enrichment was expressed in atom percent excess (A PE), which represents the increase in the percentage of ${ }^{13} \mathrm{C}$ atoms in total carbon dioxide from the combusted compounds above baseline enrichment (before isotope infusion). E nrichments were corrected for the contribution of unlabeled carbon atoms added during derivatization. Calculations were performed as described previously (5) for palmitic acid only, as this is by far the most abundant fatty acid in PC. T issue-bound and alveolar surfactant were regarded as one pool because studies in newborn rabbits showed that recycling is $\sim 16$ times faster than the de novo synthesis and clearance (20). The first appearance of enrichment was defined as the time delay between the start of the $\left[\mathrm{U}-{ }^{13} \mathrm{C}\right]$ glucose infusion and the detection of enriched palmitic acid in surfactant PC. The first appearance of enrichment was calculated by plotting the regression line for the linear increase of the enrichment-versus-time curve, and extrapolating it to baseline enrichment. The fractional synthesis rate (FSR) of palmitic acid was expressed as the percentage of the total surfactant PC palmitate pool synthesized from glucose per day. It was calculated by dividing the slope of the linear increase in enrichment of PC palmitate by the steady state enrichment of plasma glucose $(5,21)$. The absolute synthesis rate (A SR ) of surfactant PC from glucose only, was calculated by multiplying the FSR by the total lung Sat PC pool size. The value for the total lung Sat PC pool was the Sat PC pool size measured at birth in seven similar baboons $(\sim 38$ $\mu \mathrm{mol}$ of Sat PC per kilogram) plus the amount of Sat PC in the exogenous surfactant given to the animals at birth $(\sim 68 \mu \mathrm{mol}$ of Sat PC per kilogram) (2).

\section{Data Analysis}

$D$ ata are presented as means \pm standard error. The nonparametric $\mathrm{M}$ ann-W hitney $U$ test was applied to compare groups. A value of $p<$ 0.05 was accepted as significant.

\section{RESULTS}

The six control baboons and the four baboons exposed prenatally to betamethasone (beta group) had similar birth weights: $394 \pm 65$ and $340 \pm 27 \mathrm{~g}$, respectively. The two groups had similar $\mathrm{PO}_{2}$ and $\mathrm{PCO}_{2}$ values while on similar ventilatory settings as reported previously (2).

The ${ }^{13} \mathrm{C}$ enrichment of plasma glucose reached similar steady states in all baboons during the period of isotope infusion ( $3.29 \pm 0.38$ in controls and $3.29 \pm 0.16 \mathrm{APE}$ in the beta group). The mean curves for ${ }^{13} \mathrm{C}$ enrichment of palmitic acid in surfactant PC recovered from tracheal aspirates for both groups are shown in Figure 1. The first appearance of enrichment in surfactant PC was similar at $27.6 \pm 2.4 \mathrm{~h}$ for controls and $26.0 \pm 4.5 \mathrm{~h}$ for the beta group (Table 1 ). The ${ }^{13} \mathrm{C}$ enrichment of PC palmitate increased linearly in both groups and the enrichment was significantly higher in the beta group as compared with the control group during the interval from 48 to $96 \mathrm{~h}(\mathrm{p}<0.05)$. The FSR was significantly increased in

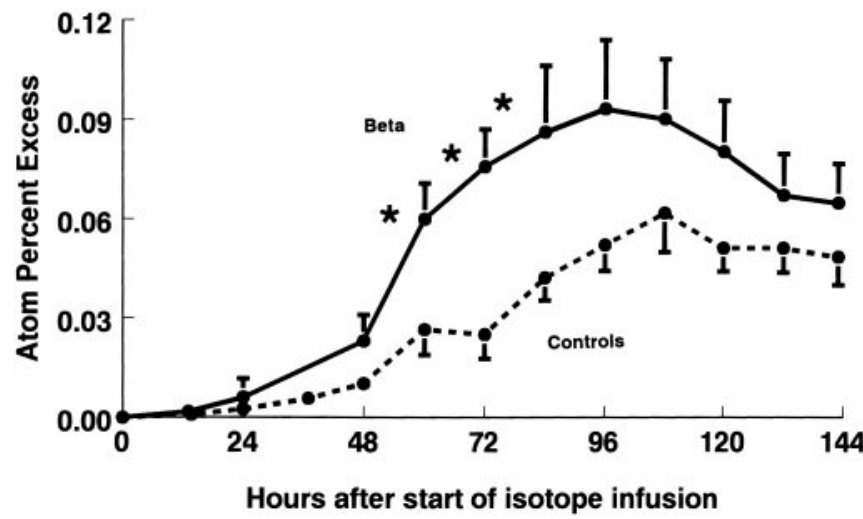

Figure $1 .{ }^{13} \mathrm{C}$ labeling of palmitic acid of surfactant phosphatidylcholine (PC) (expressed in atom percent excess, APE) after a 24-h $\left[\mathrm{U}-{ }^{13} \mathrm{C}\right]$ glucose infusion. Pregnant baboons received either prenatal betamethasone or saline. When error bars are not visible, they coincide with the markers. The increased synthesis of PC palmitate after betamethasone is shown by the increased incorporation of ${ }^{13} \mathrm{C}$ during the first days of life (*p $\left.<0.05\right)$. 
TABLE 1

MEASUREMENT OF ${ }^{13} \mathrm{C}$ ENRICHMENT AND KINETICS OF PC PALMITATE IN

BABOONS EXPOSED OR NOT EXPOSED TO PRENATAL BETAMETHASONE

\begin{tabular}{lccccc}
\hline & First Appearance & Maximal \\
of Enrichment & Enrichment & Time & Fractional & Absolute \\
& $(\mathrm{h})$ & $(\mathrm{h})$ & $\begin{array}{c}\text { Synthesis } \\
\text { Rate } \\
(\% / \mathrm{d})\end{array}$ & $\begin{array}{c}\text { Synthesis } \\
\text { Rate }\end{array}$ & $\begin{array}{c}\text { Lung Sat PC } \\
\text { Pool on Day 6 } \\
(\mu \mathrm{mol} / \mathrm{kg} / \mathrm{d})\end{array}$ \\
\hline Control group & $27.6 \pm 2.4$ & $107 \pm 3$ & $0.7 \pm 0.1$ & $0.7 \pm 0.1$ & $186 \pm 32$ \\
Beta group & $26.0 \pm 4.5$ & $90 \pm 8$ & $1.5 \pm 0.2$ & $1.6 \pm 0.3$ & $199 \pm 13$ \\
p Value & NS & 0.08 & 0.02 & 0.02 & $\mathrm{NS}$ \\
\hline
\end{tabular}

* Ten pregnant baboons were randomized to prenatal betamethasone or saline. After preterm delivery, baboons received [U- $\left.{ }^{13} \mathrm{C}\right] \mathrm{glu}-$ cose for $24 \mathrm{~h}$ and ${ }^{13} \mathrm{C}$ enrichment of palmitic acid in surfactant phosphatidylcholine (PC) was measured for $6 \mathrm{~d}$. Kinetic parameters were calculated using enrichment-versus-time curves from plasma glucose and surfactant PC palmitate, as described in MEtHODS and RESULTS. Saturated PC pool size was measured after killing on Day 6. Statistical analysis to compare groups was performed with the Mann-Whitney U test.

the beta group $(1.5 \pm 0.2 \% / d)$ compared with controls $(0.7 \pm$ $0.1 \% / d, p<0.02$, Table 1 ) as shown by the increased slopes of the enrichment-versus-time curves of PC palmitate in the beta group compared with the slopes in the control group (Figure 2). The A SR of Sat PC from glucose was higher in the beta group $(1.6 \pm 0.3 \mu \mathrm{mol} / \mathrm{kg} / \mathrm{d})$ compared with the control group $(0.7 \pm 0.1 \mu \mathrm{mol} / \mathrm{kg} / \mathrm{d}, \mathrm{p}<0.02)$. O n Day 6 , the total lung Sat PC pool size (alveolar wash plus lung tissue) was similar for the control and beta groups (Table 1). The time of maximal enrichment tended to be earlier in the beta group (90 $\pm 8 \mathrm{~h}$ ) than in the control group (107 $\pm 3 \mathrm{~h}, \mathrm{p}=0.08)$. The enrichments at $6 \mathrm{~d}$ in tracheal aspirates, alveolar washes, and lung homogenates were similar for the individual animals, and the mean values for the control and beta groups also were similar (tracheal aspirates, $0.052 \pm 0.030$; alveolar washes, $0.050 \pm$ 0.023; and lung homogenates, $0.056 \pm 0.026$ A PE ). This implies that the enrichment of surfactant $P C$ palmitate measured from tracheal aspirates is a good reflection of surfactant PC in the alveoli and tissue and is in agreement with a fast recycling of surfactant phospholipids (20).

\section{DISCUSSION}

A n understanding of surfactant metabolism is necessary to optimize treatment of the very premature human infant with sur- factant deficiency and possibly other diseases with decreased surfactant function. We infused the stable isotope $\left[\mathrm{U}-{ }^{13} \mathrm{C}\right] \mathrm{glu}$ cose in very premature baboons for $24 \mathrm{~h}$ and measured ${ }^{13} \mathrm{C}$ incorporation into palmitic acid in PC in the alveolar compartment. The ${ }^{13} \mathrm{C}$-labeled PC increased slowly, reached the maximum value more than $4 \mathrm{~d}$ after the start of the isotope infusion, and remained high at $D$ ay 6 . These data show that the endogenous synthesis and secretion of $P C$ is a slow process and that endogenously synthesized surfactant remains in the lung for a long time in the preterm primate. Five days after birth, the baboons also received an intravenous bolus of radioactive palmitate labeled with ${ }^{3} \mathrm{H}$ and the specific activity in surfactant PC was measured at killing $24 \mathrm{~h}$ later, as described (2). The percentage of surfactant PC secreted to the alveoli was only $\sim 7.5 \%$ in $24 \mathrm{~h}$. This slow rate of secretion is compatible with the kinetics calculated from the stable isotope data. A slow metabolism of surfactant has been described in nonprimate animals. In studies of newborn rabbits and lambs, maximal alveolar enrichments were found 35 to $60 \mathrm{~h}$ after a single injection of radiolabeled palmitic acid $(20,22,23)$. In term newborn sheep and term newborn rabbits, half-lives of $\left[{ }^{3} \mathrm{H}\right]$ palmitate in surfactant PC were $\sim 11.6$ and 2-4.5d, respectively $(20,24,25)$.

In comparison with human preterm infants, the first appearance of enrichment in the alveolar compartment was significantly later in the baboons ( $\sim 27$ versus $\sim 19$ h) (5). The
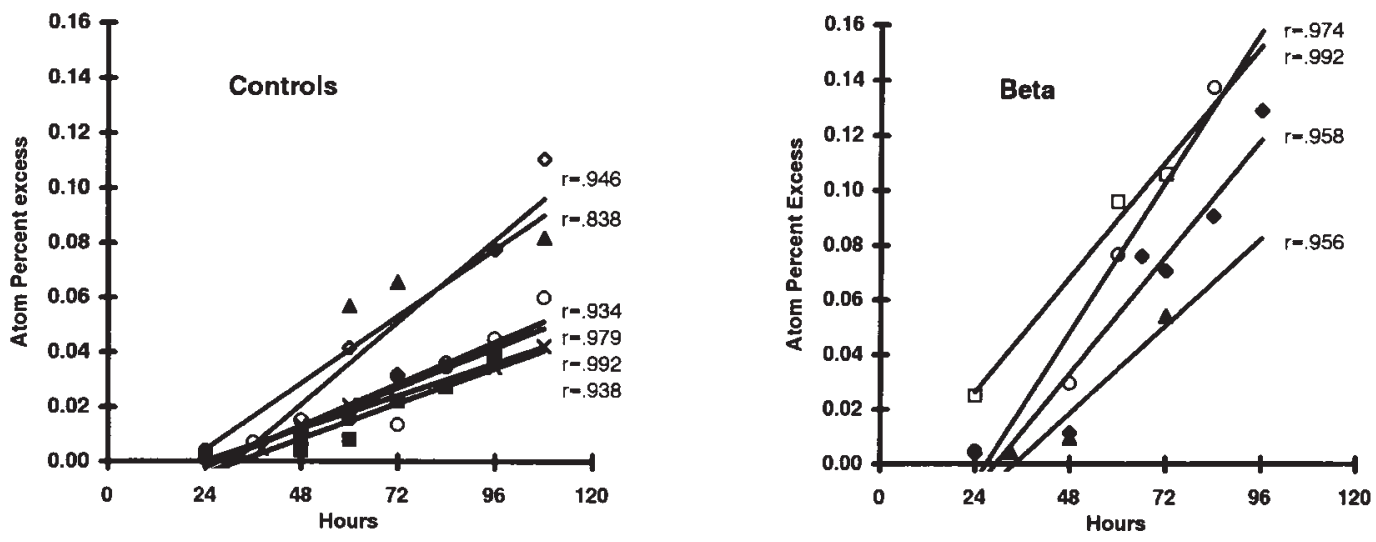

Figure 2. Linear increase in ${ }^{13} \mathrm{C}$ enrichment of palmitic acid in surfactant phosphatidylcholine (PC). Pregnant baboons received either prenatal betamethasone (beta) or saline (controls). The regression line for each preterm baboon is shown. For calculation of the time delay of first appearance of enrichment, the regression line was extrapolated to zero enrichment. The fractional synthesis rate (FSR) was calculated by dividing the slope of the regression line by steady state enrichment of plasma glucose. As plasma glucose enrichment was identical in both groups, the increased FSR is directly represented by the increased slopes in the betamethasone group compared with the control group. 
time of maximal enrichment in steroid-treated baboons ( $~ 90 \mathrm{~h})$ was comparable to the time of maximal enrichment in steroidtreated human preterm infants $(\sim 70 \mathrm{~h})$. In the present study, the absolute production of Sat PC from glucose in the beta group of $\sim 1.6 \mu \mathrm{mol} / \mathrm{kg} / \mathrm{d}$, was lower than $\sim 4.3 \mu \mathrm{mol} / \mathrm{kg} / \mathrm{d}$ in preterm human infants treated with prenatal corticosteroids and exogenous surfactant (5). These comparisons suggest a slower surfactant synthesis from glucose in the preterm baboon as compared with the human preterm infant, but do not show the contributions of other precursors. These baboons were more immature than the preterm human infants, which may explain the lower synthesis rates. The effects of gestational age or degree of lung immaturity have not been evaluated by these techniques in either preterm humans or baboons.

We also found that prenatal corticosteroids significantly stimulated the incorporation of palmitate derived from glucose into PC: the FSR in the beta group was increased by 129\% relative to controls and the absolute production rate was increased in the beta group by $\sim 128 \%$ relative to controls (Table 1). The PC palmitate tended to be maximally enriched earlier in the beta group $(\sim 90 \mathrm{~h})$ than in the controls $(\sim 107 \mathrm{~h}$, $p<0.08$, Table 1, Figure 1 ), which is also compatible with stimulated ${ }^{13} \mathrm{C}$ incorporation from plasma glucose into PC palmitate by betamethasone.

In vitro studies support the idea that glucocorticoids enhance surfactant synthesis (8-10). G lucose incorporation into surfactant PC in perfused rat lungs is increased by betamethasone (26). H owever, data on pool size measurements as an indication of surfactant synthesis in vivo are conflicting. In some studies with newborn rabbits, preterm monkeys, and lambs chronically catheterized in utero, corticosteroid treatment 2-3 d before delivery increased surfactant PC pool sizes in alveolar lavage and lung tissue significantly after birth (27-30). In contrast, other studies in large animals show no prenatal steroidinduced increase in the alveolar $(9,31-34)$ or total lung Sat PC pool size after birth $(9,31-33)$. Ballard and coworkers and Ikegami and colleagues did not find an increase in total lung Sat PC pool size at birth in preterm lambs when glucocorticoids were administered 2 to $4 \mathrm{~d}$ before preterm delivery ( 11 , 31). H owever, when steroids were administered 1 wk before delivery, the total lung Sat PC pool sizes at birth increased significantly $(11,31)$. In the present study, we did not measure surfactant PC pool sizes at birth. We demonstrated that the processes of synthesis and secretion are slow and that the production rate of Sat PC from glucose in preterm newborns is low compared with the total Sat PC pool on D ay 6. Therefore, the pool size will not increase significantly until several days after exposure to betamethasone. This low synthesis rate relative to the pool size may explain why most studies find long delays between prenatal glucocorticoid treatment and increased surfactant PC pools $(11,31)$.

The dosage and exposure time to steroids, the species ( $48 \mathrm{~h}$ of exposure in a rat is relatively long compared with lambs or baboons), and the experimental conditions that could cause secondary stress to the fetus also may contribute to discrepancies in the various reports of steroids on surfactant metabolism.

In the present study, there was no effect of prenatal betamethasone treatment on Sat PC pool size in total lung at D ay 6 (Table 1). Probably physiological changes after birth and therapeutic interventions such as ventilation have larger effects on surfactant metabolism than do prenatal glucocorticoids. Such effects are consistent with the findings by Seidner and coworkers, who showed that the lung tissue Sat PC pool size was larger in the very preterm baboon after $6 \mathrm{~d}$ of ventilation ( $125 \mathrm{~d}$ of gestation plus $6 \mathrm{~d}$ of ventilation) than in either the near term baboon ( $175 \mathrm{~d}$ of gestation) or the adult baboon
(2). A theoretical explanation for the fact that we did not find increased pool sizes on Day 6 could be that prenatal betamethasone stimulates both synthesis and clearance of surfactant as shown by Fiascione and colleagues in preterm rabbits (35). However, in the present study the clearance of exogenous labeled surfactant was not increased (2).

In the type II pneumocyte, glucose is a primary precursor for fatty acids used for the synthesis of surfactant PC. This is especially true in a state of relative fatty acid deficiency, as in the present study $(36,37)$. The baboons did not receive any lipids during the entire study period, and the fat stores in these very premature baboons are minimal. Sanders and coworkers showed that the conversion of glucose to palmitic acid is a fast process (38). 0 ther substrates for surfactant PC are present as well, such as intracellular glycogen, fatty acids, lactate, pyruvate, and ketone bodies. The overall kinetics for surfactant PC presented, and the increased synthesis rates after glucocorticoids administration, are measured from glucose only and may not represent total surfactant synthesis. The synthesis rates are valid from this precursor but are probably underestimations; a more direct precursor of PC palmitate such as palmitic acid may yield more accurate estimations of absolute synthesis rates but ignores the importance of lipogenesis in the type II cell. It is, in the present study, unclear whether prenatal steroid stimulates the use of other precursors and how they influence glucose enrichment in the type II cell. In vitro, steroids increase glycogenolysis in the type II cell, which is associated with synthesis of surfactant PC; whether this occurs in the living primate has not been studied. If prenatal steroids increased glycogenolysis in the type II cell during the period of labeled glucose incorporation into surfactant PC palmitate, then the glucose as a precursor would be diluted, resulting in a lower enrichment of surfactant PC palmitate after steroids. We found, however, increased ${ }^{13} \mathrm{C}$ enrichment of surfactant PC palmitate. It is unlikely that glycogen depletion had already occurred before birth, as in a few baboons no glycogen depletion was found by electron microscopy after $6 \mathrm{~d}$ of ventilation (2). G lucose can be used to describe surfactant metabolism, to evaluate differences between groups, and to study effects of interventions and clinical conditions. In addition, glucose can be used safely and easily in critically ill preterm human infants.

In conclusion, the data show that endogenous surfactant synthesis and turnover are slow processes. The endogenous synthesis of surfactant PC from glucose is stimulated within $48 \mathrm{~h}$ by prenatal betamethasone after delivery of the very premature baboon.

Acknowledgment: The writers thank Ingrid H. T. Luijendijk, Ad de Bruijn, and Annemiek de Raadt (Department of Pediatrics, Erasmus University Rotterdam) for excellent technical assistance.

\section{References}

1. Ikegami, M., A. H. J obe, T. Y amada, A . Priestly, L. R uffini, E. R ider, and S. R. Seidner. 1989. Surfactant metabolism in surfactant-treated preterm ventilated lambs. J . A ppl. Physiol. 67:429-437.

2. Seidner, S. R., A. H. J obe, J.J . Coalson, and M. Ikegami. 1998. A bnormal surfactant metabolism and function in preterm ventilated baboons. A m. J. Respir. Crit. Care M ed. 158:1982-1989.

3. Jackson, J. C., S. Palmer, W. E. Truog, T. A. Standaert, J. H. M urphy, and W. A. Hodson. 1986. Surfactant quantity and composition during recovery from hyaline membrane disease. P ediatr. R es. 20:1243-1247.

4. Hallman, M., T. A . M erritt, M. Pohjavuori, and L. G luck. 1986. E ffect of surfactant substitution on lung effluent phospholipids in respiratory distress syndrome: evaluation of surfactant phospholipid turnover, pool size, and the relationship to severity of respiratory failure. Pediatr. Res. 20:1228-1235.

5. Bunt, J.E. H., L.J . I. Zimmermann, J . L. D. W attimena, R. H. van B eek, 
P. J. J. Sauer, and V. P. Carnielli. 1998. Endogenous surfactant turnover in preterm infants measured with stable isotopes. A m. J. Respir. Crit. Care M ed. 157:810-814.

6. B eck, J. C., W. M itzner, J. W. J ohnson, G. M. Hutchins, J. M . Foidart, W. T. L ondon, A . E. Palmer, and R. Scott. 1981. B etamethasone and the rhesus fetus: effect on lung morphometry and connective tissue. Pediatr. Res. 15:235-240.

7. Walther, F. J., M . Ikegami, D. Warburton, and D. H. Polk. 1991. Corticosteroids, thyrotropin-releasing hormone, and antioxidant enzymes in preterm lamb lungs. Pediatr. R es. 30:518-521.

8. Pope, T. S., and S. A. R ooney. 1987. E ffects of glucocorticoid and thyroid hormones on regulatory enzymes of fatty acid synthesis and glycogen metabolism in developing fetal rat lung. Biochim. Biophys. A cta 918:141-148.

9. Chen, C. M ., M . Ikegami, T. U eda, D. H . Polk, and A . H . J obe. 1995. Exogenous surfactant function in very preterm lambs with and without fetal corticosteroid treatment. J. A ppl. P hysiol. 78:955-960.

10. Liley, H. G., R. T. White, R. G. Warr, B. J. Benson, S. Hawgood, and P. L. B allard. 1989. R egulation of messenger R NA s for the hydrophobic surfactant proteins in human lung. J. Clin. Invest. 83:1191-1197.

11. B allard, P. L., Y. Ning, D. Polk, M . I kegami, and A . H . J obe. 1997. G lucocorticoid regulation of surfactant components in immature lambs. A m. J. Physiol. 273:L 1048-L 1057.

12. Ikegami, M., D. Berry, T. Elkady, A. Pettenazzo, S. Seidner, and A. Jobe. 1987. Corticosteroids and surfactant change lung function and protein leaks in the lungs of ventilated premature rabbits. J. Clin. Invest. 79:1371-1378.

13. Folch, J., M. Lees, and H. S. Stanley. 1957. A simple method for the isolation and purification of total lipids from animal tissues. J. Biol. Chem. 226:497-509.

14. Pfaffenberger, C. D., J. Szafranek, M. G. H orning, and E. C. Horning 1975. G as chromatographic determination of polyols and aldoses in human urine as polyacetates and aldononitrile polyacetates. A nal. B iochem. 63:501-512.

15. Bligh, E. G., and W. J. D yer. 1959. A rapid method of total lipid extraction and purification. Can. J. B iochem. Physiol. 37:911-917.

16. Touchstone, J. C., J. C. Chen, and K. M . B eaver. 1979. I mproved separation of phospholipids in thin layer chromatography. L ipids 15:61-62.

17. Carnielli, V. P., E. J. Sulkers, C. M oretti, J . L. W attimena, J. B. van G oudoever, H. J. D egenhart, F. Zacchello, and P. J. Sauer. 1994. Conversion of octanoic acid into long-chain saturated fatty acids in premature infants fed a formula containing medium-chain triglycerides. M etabolism 43:1287-1292.

18. M ason, R. J., J . N ellenbogen, and J. A . Clements. 1976. I solation of disaturated phosphatidylcholine with osmium tetroxide. J. Lipid Res. 17:281-284.

19. Bartlett, G. R. 1959. Phosphorus assay in column chromatography. J. Biol. Chem. 234:466-468.

20. J acobs, H., A. H. J obe, M. I kegami, and S. J ones. 1982. Surfactant phosphatidylcholine source, fluxes, and turnover times in 3-day-old, 10day-old, and adult rabbits. J. Biol. Chem. 257:1805-1810.

21. Ballmer, P. E ., M . A . M cN urlan, E. M ilne, S. D. H eys, V. B uchan, A . G. Calder, and P. J. G arlick. 1990. M easurement of albumin synthesis in humans: a new approach employing stable isotopes. A m. J. Physiol. 259:E 797-E 803.

22. Ikegami, M., A . H . J obe, and P. W. Nathanieltsz. 1981. The labeling of pulmonary surfactant phosphatidylcholine in newborn and adult sheep. Exp. L ung Res. 2:197-206.
23. J obe, A ., M . I kegami, I. Sarton-M iller, and L. B arajas. 1980. Surfactant metabolism of newborn lamb lungs studied in vivo. J. A ppl. Physiol. 49:1091-1098.

24. G latz, T., M . I kegami, and A. H . J obe. 1982. M etabolism of exogenously administered natural surfactant in the newborn lamb. Pediatr. R es. 16: 711-715.

25. Jobe, A. H., E. K irkpatrick, and L. Gluck. 1978. Lecithin appearance and apparent biologic half-life in term newborn rabbit lung. Pediatr. Res. 12:669-675.

26. Patterson, C. E., K. S. D avis, D. E. B eckman, and R. A . R hoades. 1986. Fatty acid synthesis in the fetal lung: relationship to surfactant lipids. Biochim. B iophys. A cta 878:110-126.

27. Rooney, S. A ., L. I. Gobran, P. A . Marino, W. M. Maniscalco, and I. $\mathrm{G}$ ross. 1979. E ffects of betamethasone on phospholipid content, composition and biosynthesis in the fetal rabbit lung. Biochim. Biophys. A cta 572:64-76.

28. K essler, D. L., W. E. Truog, J. H. M urphy, S. Palmer, T. A. Standaert, D.E. Woodrum, and W. A. Hodson. 1982. Experimental hyaline membrane disease in the premature monkey: effects of antenatal dexamethasone. A m. Rev. Respir. D is. 126:62-69.

29. W arburton, D ., L. Parton, S. B uckley, L. Cosico, G . Enns, and T. Saluna. 1988. Combined effects of corticosteroid, thyroid hormones, and betaagonist on surfactant, pulmonary mechanics, and beta-receptor binding in fetal lamb lung. Pediatr. Res. 24:166-170.

30. Platzker, A. C., J. A. Kitterman, E. J. M escher, J. A . Clements, and W. H. Tooley. 1975. Surfactant in the lung and tracheal fluid of the fetal lamb and acceleration of its appearance by dexamethasone. Pediatrics 56:554-561.

31. Ikegami, M., D. H. Polk, A . H . J obe, J. N ewnham, P. Sly, R. K ohan, and R. K elly. 1996. E ffect of interval from fetal corticosteroid treatment to delivery on postnatal lung function of preterm lambs. J. A ppl. Physiol. 80:591-597.

32. Ikegami, M ., D. H . Polk, A . H . J obe, J . Newnham, P. Sly, R . K ohen, and R. K elly. 1995. Postnatal lung function in lambs after fetal hormone treatment. E ffects of gestational age. A m. J. Respir. Crit. Care M ed. 152:1256-1261.

33. Ikegami, M., D. Polk, and A. Jobe. 1996. M inimum interval from fetal betamethasone treatment to postnatal lung responses in preterm lambs. A m. J. O bstet. G ynecol. 174:1408-1413.

34. Polk, D. H., M. I kegami, A. H . J obe, J. N ewnham, P. Sly, R. K ohen, and R. K elly. 1995. Postnatal lung function in preterm lambs: effects of a single exposure to betamethasone and thyroid hormones. A m. J. O bstet. G ynecol. 172:872-881.

35. Fiascone, J. M., M. R. M ercurio, D. M. Lima, and H. C. Jacobs. 1990. Corticosteroids and intratracheal surfactant both alter the distribution between the airways and lung tissue of intratracheally administered radiolabeled phosphatidylcholine in the preterm rabbit. Exp. L ung Res. 16:311-321.

36. M aniscalco, W. M., J . N . Finkelstein, and A . B. Parkhurst. 1983. D e novo fatty acid synthesis by freshly isolated alveolar type II epithelial cells. Biochim. Biophys. A cta 751:462-469.

37. B atenburg, J. J., W. J. L ongmore, and L. M . van G olde. 1978. The synthesis of phosphatidylcholine by adult rat lung alveolar type II epithelial cells in primary culture. B iochim. Biophys. A cta 529:160-170.

38. Sanders, R. L., M. J. Engle, and W. H. D ouglas. 1981. Effect of dexamethasone upon surfactant phosphatidylcholine and phosphatidylglycerol synthesis in organotypic cultures of type II cells. Biochim. Biophys. A cta 664:380-388. 